\title{
EXPRESSION OF INSULIN-LIKE GROWTH FACTOR RECEPTOR TYPE 1 CORRELATES WITH LYMPHATIC METASTASES IN HUMAN GASTRIC CANCER
}

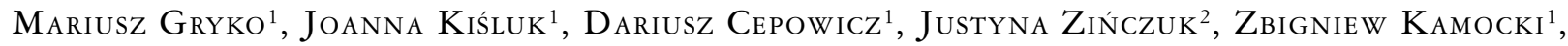 \\ Katarzyna Guzińska-Ustymowicz², Anna Pryczynicz ${ }^{2}$, Jolanta Czyżewska ${ }^{3}$, \\ Andrzej Kemona ${ }^{2}$, Bogusław Kędra ${ }^{1}$
}

\begin{abstract}
${ }^{1} 2^{\text {nd }}$ Department of General and Gastroenterological Surgery of the Medical University of Bialystok ${ }^{2}$ Department of General Pathomorphology, Medical University of Bialystok, Poland

${ }^{3}$ Department of Clinical Laboratory Diagnostics, Medical University of Bialystok, Poland
\end{abstract}

\begin{abstract}
Most patients with gastric cancer are diagnosed at advanced clinical stages with a high frequency of lymph node metastasis. It is very important to find novel factors for the early diagnostic and prognostic evaluation of gastric cancer. It has been shown that IGF-1R activates mitotic division and inhibits apoptosis of cancer cells through the activation of signaling MAP/ERK and PI3K/Akt-1 pathways. IGF-1R plays a role in cell transformation and maintenance of the phenotype in modified cells. Moreover, an IGF-1 receptor effect influences the processes of adhesion, migration, invasion and metastasis of tumor cells. The aim of the study was to assess the expression of IGF-1R in gastric carcinoma in correlation with selected anatomo-clinical parameters.

The study enrolled a group of 49 patients treated surgically for gastric cancer. 28 patients had no lymph node metastases. The expression of the studied proteins was assessed using the immunohistochemical method.

We found that the expression of IGF-1R in gastric cancer is associated with lymph node metastasis ( $\mathrm{p}<0.001)$, is correlated with worse prognosis and high histological malignancy grade, and is an independent predictor of survival in patients with gastric cancer $(\mathrm{p}<0.001)$.

IGF-1R may play an important role in tumor growth and metastasis via the lymphatic pathway.
\end{abstract}

Key words: cancer metastases, gastric cancer, gastric cancer metastasis, insulin-like growth factor receptor $1, \mathrm{IGF}-1 \mathrm{R}$.

\section{Introduction}

Gastric cancer (GC) is one of the most frequently diagnosed malignant neoplasms. Every year approximately one million new GC cases are diagnosed globally. Gastric cancer is characterized by high mortality - it is the third most common cause of death from cancer worldwide $[1,2]$. The genetic bases underlying gastric tumorigenesis and progression are still largely unknown. Most patients with gastric cancer are diagnosed at advanced clinical stages with a high rate of lymph node metastasis. Although the tumor (T) node (N) metastasis (M) stage is still the most important prognostic factor for gastric cancer, the prognosis varies among patients at the same stage. It is very important to find novel factors for the early diagnostic and prognostic evaluation of gastric cancer.

Insulin-like growth factor receptor (IGF-1R) is a transmembrane glycoprotein, a tetramer of two 
identical $\alpha$-subunits and two identical $\beta$-subunits connected by disulfide bonds [3]. Structurally, IGF-1R belongs to the tyrosine kinase receptor family and resembles the insulin receptor - there is $60 \%$ homology between them. The expression of IGF-1R is regulated by steroid hormones and growth factors [4]. High levels of IGF-1 ligand act as a negative feedback signal to suppress the expression of the receptor and result in a decrease in IGF-1R [5]. Other growth factors (fibroblast growth factor, platelet-derived growth factor, epidermal growth factor) and estrogens, glucocorticoids, growth hormone, follicle-stimulating hormone, luteinizing hormone and thyroid hormones positively stimulate the expression of this receptor $[4,6]$. IGF-1R activation induces signal transduction pathways: by activating protein Ras/ Raf and mitogen-activated protein kinase (MAPK) or by engaging phosphatidylinositide-3-kinase (PI3K) [4]. IGF-1R plays a role in cell transformation and maintenance of the phenotype in modified cells [7]. Moreover, IGF-1R influences the processes of adhesion, migration, invasion and metastasis of tumor cells $[8,9]$. It has been shown that IGF-1R activates the mitotic divisions and inhibit apoptosis of cancer cells through the activation of signaling MAP/ERK and PI3K/Akt-1 pathways [6, 10]. Overexpression of IGF-1R has been observed in many cancers, including esophageal cancer [11], breast cancer [12], colorectal cancer $[13,14]$ and lung cancer [15]. Due to the important contribution of this receptor to the process of carcinogenesis and metastasis, research on using IGF-1R as a therapeutic target in oncology is being conducted $[16]$.

The aim of the current study was to assess the expression of IGF-1R in gastric carcinoma in correlation with anatomo-clinical parameters.

\section{Material and methods}

The study enrolled a group of 49 patients treated surgically for gastric cancer in the Department of Surgery. $4 \mu \mathrm{m}$ thick sections were cut from paraffin blocks and stained with hematoxylin-eosin (HE). The routine histopathological assessment included tumor location, histological type, grade (G), stage (pTN) and the presence of metastases to local lymph nodes. Gastric carcinomas were divided according to Lauren's [17], Goseki's [18] and Kubo's [19] classifications.

\section{Immunohistochemical analysis}

Formalin-fixed and paraffin embedded tissue specimens were cut on a microtome into $4 \mu \mathrm{m} \mathrm{sec}-$ tions. The sections were deparaffinized in xylene and hydrated in alcohol. Antigens were exposed through citrate buffer heating $(\mathrm{pH}=6.0)$ for 20 minutes and then cooled for at least $20 \mathrm{~min}$ at room temperature. After washing with distilled water and with PBS buffer $(\mathrm{pH}=7.2)$ tissue sections were covered for 5 min with peroxidase blocking reagent (Novolink Polymer Detection System, Novocastra) to block endogenous peroxidase, followed by an additional wash with the supplied buffer. Individual slides were then incubated for 24 hours at room temperature with anti-IGF-1R antibody (dilution $1: 50$ ), in the antibody diluent buffer. The slides were washed thrice with the buffer and then incubated with Post Primary Block (Novolink Polymer Detection System, Novocastra) for $30 \mathrm{~min}$ at room temperature after extensive washing with TRIS. Next incubation was performed with Novolink Polymer (30 min and washing with TRIS; Novolink Polymer Detection System, Novocastra). The color reaction was developed in DAB Chromogen (Novolink Polymer Detection System, Novocastra) according to the manufacturer's instructions. The sections were then counterstained with Meyer's hematoxylin, dehydrated, and mounted. The primary antibody solution in negative controls was substituted with a PBS buffer.

Protein expression was determined using a semiquantitative method and assessed as positive (reaction visible in $>5 \%$ of tumor cells) or negative (lack of reaction, or reaction present in $<5 \%$ of cells). Positive reactions were assessed in at least 500 cancer cells in each tissue specimen under a light microscope $(400 \times)$.

\section{Statistical analysis}

Statistical analysis was conducted using Fisher's test and Pearson's $\chi^{2}$ test. Log-rank test (F Cox test) according to the Kaplan-Meier survival analysis approach was employed to compare the overall survival rates of patients. A p-value $<0.05$ was considered statistically significant.

\section{Results}

\section{Patient characteristics}

The 49 cases were selected randomly and included all stages and histological types of gastric cancer. The patients consisted of 18 women and 31 men, and their mean age was 64 years. pT3 was found in $65.3 \%$ and in 28 patients lymph node metastases were not found. Histological grade of tumors was assessed as poorly or moderately differentiated. The study group consisted of 33 diffuse, 1 intestinal and 15 mixed histological type cancer. Patient characteristics are detailed in Table I.

\section{Expression of IGF-1R in primary gastric cancer}

IGF-1R positive expression in primary tumor was observed in 25 patients (51\%). Statistical analysis revealed no correlation between IGF-1R expression 
Table I. Patients' characteristics. Association between IGF-1R expression in primary gastric cancer and clinicopathological characteristics

\begin{tabular}{|c|c|c|c|c|c|c|}
\hline \multirow{2}{*}{ CharaCteristics } & & \multicolumn{2}{|c|}{ Patients $(\mathrm{N}=49)$} & \multicolumn{2}{|c|}{ IGF-1R EXPRESSION } & \multirow[b]{2}{*}{$\mathrm{P}^{\#}$ VALUE } \\
\hline & & \multirow{2}{*}{$\begin{array}{l}\mathbf{N} \\
19 \\
\end{array}$} & \multirow{2}{*}{$\begin{array}{c}\% \\
38.78 \\
\end{array}$} & \multirow{2}{*}{$\begin{array}{c}(-) \text { NEGATIVE } \\
(\mathrm{N}=24) \\
12\end{array}$} & \multirow{2}{*}{$\begin{array}{c}(+) \text { POSITIVE } \\
(\mathrm{N}=25) \\
7\end{array}$} & \\
\hline Age & $\leq 60$ & & & & & \multirow{3}{*}{0.114} \\
\hline & $>60$ & 30 & 61.22 & 12 & 18 & \\
\hline Median: & 64 & & & & & \\
\hline \multirow[t]{2}{*}{ Sex } & Male $(n=31)$ & 31 & 63.23 & 14 & 17 & \multirow{2}{*}{0.482} \\
\hline & Female $(\mathrm{n}=18)$ & 18 & 36.74 & 10 & 8 & \\
\hline \multirow{3}{*}{$\begin{array}{l}\text { Gastric } \\
\text { tumor } \\
\text { location: }\end{array}$} & $1 / 3$ lower & 2 & 4.08 & 1 & 1 & \multirow{3}{*}{0.573} \\
\hline & $1 / 3$ middle & 20 & 40.82 & 8 & 12 & \\
\hline & $1 / 3$ upper & 27 & 55.1 & 15 & 12 & \\
\hline \multirow{3}{*}{$\begin{array}{l}\text { Depth of wall } \\
\text { invasion: }\end{array}$} & pT1 & 8 & 16.32 & 2 & 6 & \multirow[t]{3}{*}{0.225} \\
\hline & $\mathrm{pT} 2$ & 9 & 18.36 & 6 & 3 & \\
\hline & $\mathrm{pT} 3$ & 32 & 65.3 & 16 & 16 & \\
\hline \multirow{4}{*}{$\begin{array}{l}\text { Lymph node } \\
\text { metastasis*: }\end{array}$} & $\mathrm{pN} 0$ & 28 & 57.14 & 23 & 5 & \multirow{4}{*}{$<0.001$} \\
\hline & $\mathrm{pN} 1$ & 10 & 20.41 & 1 & 9 & \\
\hline & $\mathrm{pN} 2$ & 11 & 22.45 & 0 & 11 & \\
\hline & $\mathrm{pN} 3$ & 0 & 0 & & & \\
\hline \multirow{3}{*}{$\begin{array}{l}\text { Histological } \\
\text { grade: }\end{array}$} & (G1) well differentiated & 0 & 0 & 0 & 0 & \multirow{3}{*}{0.031} \\
\hline & $\begin{array}{l}\text { (G2) moderately } \\
\text { differentiated }\end{array}$ & 25 & 51.02 & 16 & 9 & \\
\hline & (G3) poorly differentiated & 24 & 48.98 & 8 & 16 & \\
\hline \multirow{3}{*}{$\begin{array}{l}\text { Lauren } \\
\text { classification: }\end{array}$} & intestinal & 1 & 2.04 & 1 & 0 & \multirow{3}{*}{0.446} \\
\hline & diffuse & 33 & 67.35 & 17 & 16 & \\
\hline & mixed & 15 & 30.61 & 6 & 9 & \\
\hline \multirow{4}{*}{$\begin{array}{l}\text { Goseki’s } \\
\text { classification: }\end{array}$} & $\mathrm{I}$ & 8 & 16.33 & 4 & 4 & \multirow{4}{*}{0.998} \\
\hline & II & 14 & 28.57 & 7 & 7 & \\
\hline & III & 8 & 16.33 & 4 & 4 & \\
\hline & IV & 19 & 38.78 & 9 & 10 & \\
\hline \multirow{3}{*}{$\begin{array}{l}\text { Histologic type } \\
\text { by Kubo's } \\
\text { classification: }\end{array}$} & non-mucinous & 37 & 75.51 & 18 & 19 & \multirow{3}{*}{0.577} \\
\hline & mucinous & 11 & 22.45 & 5 & 6 & \\
\hline & anaplastic & 1 & 2.04 & 1 & 0 & \\
\hline
\end{tabular}

* NO = 0 nodes involved; $N 1=1-6$ nodes involved; $N 2=7-15$ nodes involved; $N 3>15$ nodes

\# Pearson's $\chi^{2}$ test was performed. Significant values $(p<0.050)$ are shown in bold

in the main tumor mass and clinico-pathological parameters, such as age, gender, tumor location, depth of wall invasion and classifications of Lauren, Goseki and Kubo (Table I). A statistically significant relationship was observed between IGF-1R expression and grade of histological malignancy $(\mathrm{G})(\mathrm{p}=$ $=0.031)$. According to the data presented in the table, positive IGF-1R expression was associated with moderately (9/49) and poorly (16/49) differentiated carcinoma. Positive IGF-1R expression is presented in Fig. 1 and Fig. 2. Fig. 3 - lack of IGF-1R expression in poorly differentiated tumor G3.

Also a very significant correlation was found between local lymph node involvement $(\mathrm{pN})$ and positive IGF-1R expression ( $\mathrm{p}<0.001$ ). Positive IGF-1R expression in the main mass of the tumor was detected in as many as $95.23 \%$ (20/21 cases) of patients with lymph node involvement (N1 + N2). Only $5 / 49$ tumors had positive expression of IGF-1R and were free of lymph node metastases. 
Table II. Association of IGF-1R expression in primary tumor and lymph node metastasis. *

\begin{tabular}{ccc}
\hline IGF-1R EXPRESSION IN PRIMARY TUMOR & \multicolumn{2}{c}{ IGF-1R EXPRESSION IN LYMPH NODE METASTASIS, N $(\%)$} \\
\cline { 2 - 3 } & NEGATIVE $(\mathrm{N}=31)$ & POSITIVE $(\mathbf{N}=18)$ \\
\hline negative $(\mathrm{n}=24)$ & $11(24.44)$ & $13(24.44)$ \\
\hline positive $(\mathrm{n}=25)$ & $20(40.00)$ & $5(11.11)$ \\
\hline $\begin{array}{l}* \text { Pearson's } \chi^{2} \text { test was performed to determine the statistical significance of relationships between IGF-1R expression in primary tumor and lymph node metastasis; } \\
p=0.013\end{array}$
\end{tabular}

\section{Association of IGF-1R expression in primary tumor and in lymph node metastasis}

Expression levels of IGF-1R in lymph node metastases were negatively correlated with those in the primary tumors and this association was statistically significant $(\mathrm{p}=0.013$; Table II). Positive expression in primary tumor is associated with lack of or weak reaction in lymph node metastasis. Only $5 / 25$ patients also had positive IGF-1R expression in the tumor main mass and regional lymph node metastasis.

\section{Overall patient survival analysis}

Patients' survival rate showed lack of correlation with IGF-1R expression ( $p=0.286$ ) (Fig. 4). There was no significant difference in overall survival rates between the patients with positive IGF-1R expression in the primary lesion and those with negative IGF-1R expression $(\mathrm{p}=0.286)$.

\section{Discussion}

Overexpression of IGF-1R has been reported in many human cancers [11-15]. In the literature it has been shown that this receptor plays an important role in cancer cell transformation, tumor cell survival and development $[6,20,21]$. Furthermore, it has been observed that the blockage of IGF-1R inhibits tumor development by reducing tumor angiogenesis and lymphangiogenesis [22], which suggests a potential novel target in therapeutic applications in gastrointestinal malignancies. In our study we investigated expression of the IGF-1 receptor in primary gastric cancer and lymph node metastases. As revealed by statistical analysis, positive IGF-1R expression is strongly associated with metastases to local lymph nodes and their extent, which seems to confirm earlier findings. Ge et al. [23] in an immunohistochemical study, found that IGF-1R positive expression was correlated with lymph node metastases. In their study, expression of IGF-1R in cases with a greater number of involved lymph nodes (N1, N2, N3) was weaker than in patients with N0. They also noted a significant correlation of IGF-1R expression in the primary tumor with tumor size, location, depth of wall invasion, TNM stage and differentiation status. Also in our study a significant correlation between
IGF-1R expression in the tumor main mass and histologic grade of cell differentiation was observed. We noted positive IGF-1R expression in tumors with high malignancy grade: G3 and G2 - poorly and moderately differentiated cancer cells, respectively. These observations may suggest that the tendency of IGF-1 $\mathrm{R}$ expression in tumors with high and moderate malignancy grades may be related to gastric cancer spread via the lymphatic pathway.

Jiang et al. [8] obtained similar results associating the role of IGF-1R with local lymph node metastases. Moreover, they analyzed the association between IGF-1R expression and expression of transcription factor $\mathrm{Sp} 1$, which can transactivate the IGF-1R gene promoter region [24]. In their study, the positive IGF-1R expression also positively correlated with Sp1 expression. In patients with strong $\mathrm{Sp} 1$ expression, the tumors might be more likely to have stronger IGF-1R expression. Based on statistical analysis, the authors also showed that expression levels of IGF-1R in lymph node metastases were correlated with those in the primary tumors $(\mathrm{p}=0.005)$. Our results also confirm those observations. We noted that expression in primary gastric tumor negatively correlated $(\mathrm{p}=$ $=0.013)$ with results of IGF-1R expression in involved lymph nodes.

Despite the association of IGF-1R expression with tumor grade and status of lymph node metastases, no research has shown an important correlation between degree of expression and impact on overall survival. Ge et al. [23], Jiang et al. [8] and Matsubara et al. [25] described a trend of reduced survival in patients with strong positive IGF-1R expression, but it was not statistically significant. Our results of the survival curve of patients with gastric cancer in dependence of IGF-1R expression also did not clearly prove any important influence on median survival duration.

\section{Conclusions}

In summary, we have shown that expression of IGF-1R in gastric cancer is associated with lymph node metastasis and is correlated with a high histological differentiation grade. Based on literature reports and our own data, IGF-1R may play an important role in tumor growth and metastasis via the lymphatic pathway. Analysis of expression directly 


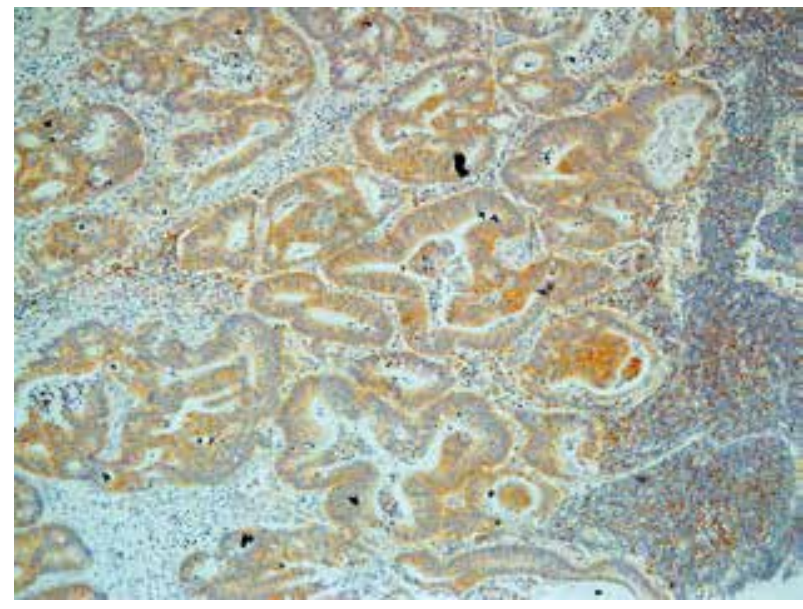

Fig. 1. Positive IGF-1R expression in moderately (G2) differentiated gastric cancer

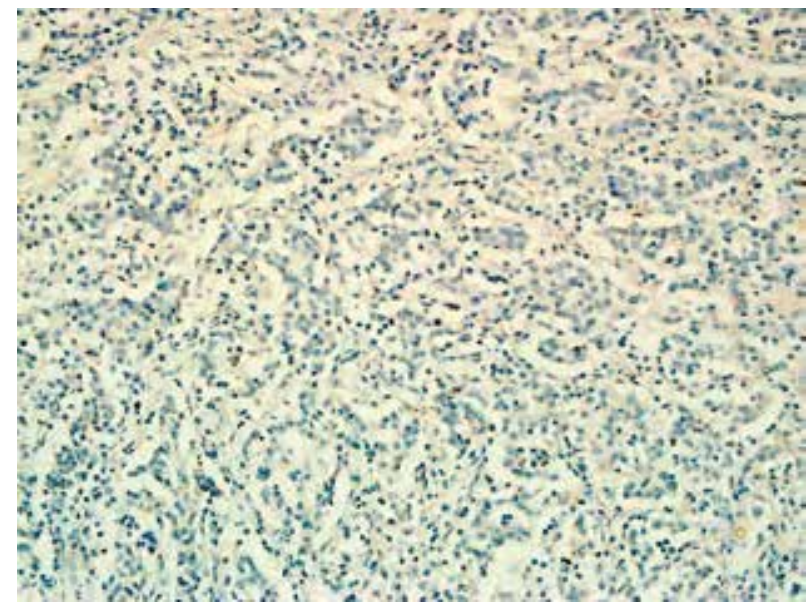

Fig. 3. Negative IGF-1R expression in poorly (G3) differentiated gastric cancer

in primary tumor tissue in our study group did not clearly prove any important influence on median survival duration, but increasing the number of patients could provide new conclusions. It seems useful to investigate this protein as an early indicator of poor prognosis in gastric cancer patients which can inform about potential high risk of metastasis development - but this requires further study in a large patient group. It also may serve as a novel therapeutic target for cancer cells.

The authors declare no conflict of interests.

\section{References}

1. Jemal A, Bray F, Melissa M, et al. Global Cancer Statistics. CA Cancer J Clin 2011; 61: 69-90.

2. Tseng CW, Lin CC, Chen CN, et al. Integrative network analysis reveals active microRNAs and their functions in gastric cancer. BMC Systems Biology 2011; 5: 99.

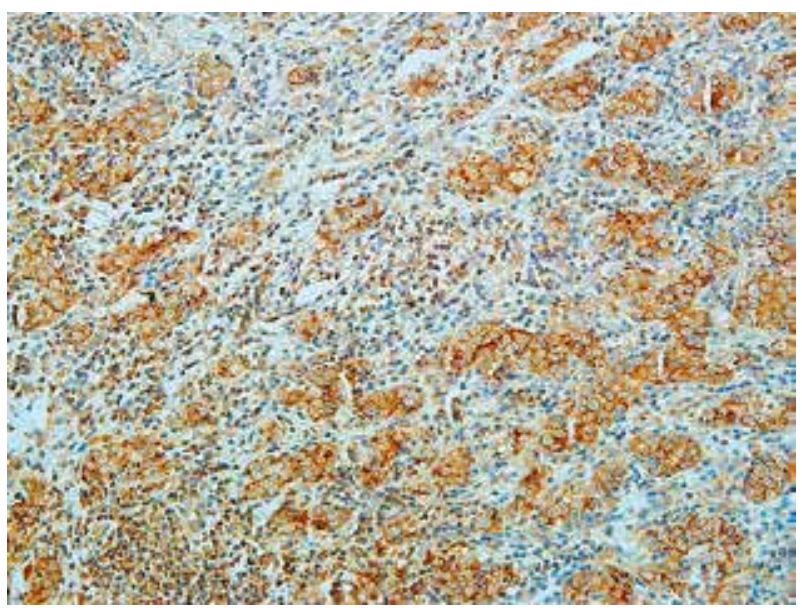

Fig. 2. Positive IGF-1R expression in poorly (G3) differentiated gastric cancer

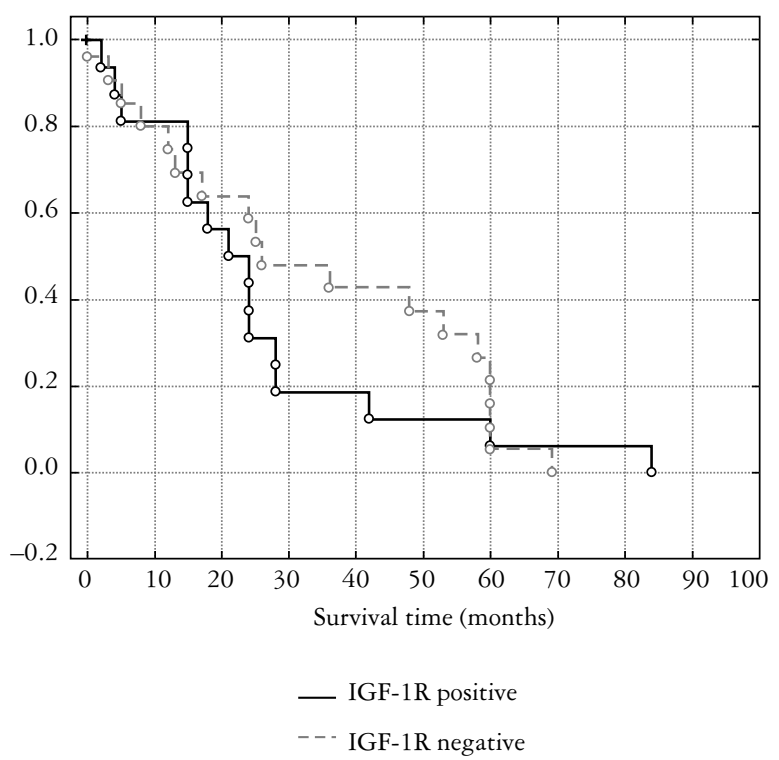

Fig. 4. Survival curve of patients with gastric cancer depending on IGF-1R expression $(\mathrm{p}=0.286)$

3. Sepp-Lorenzino L. Structure and function of the insulin-like growth factor I receptor. Breast Cancer Res Treat 1998; 47 : 235-253.

4. LeRoith D, Werner H, Beitner-Johnson D, Roberts CT Jr. Molecular and cellular aspects of the insulin-like growth factor I receptor. Endocr Rev 1995; 16: 143-163.

5. Hernandez-Sanchez C, Werner H, Roberts CT Jr, et al. Differential regulation of insulin-like growth factor-I (IGF-I) receptor gene expression by IGF-I and basic fibroblastic growth factor. J Biol Chem 1997; 272: 4663-4670.

6. Yu H, Rohan T. Role of the insulin-like growth factor family in cancer development and progression. J Natl Cancer Inst 2000; 92: 1472-1489.

7. LeRoith D, Baserga R, Helman L, Roberts CT Jr. Insulin-like growth factors and cancer. Ann Intern Med 1995; 122: 54-59.

8. Foulstone E, Prince S, Zaccheo O, et al. Insulin-like growth factor ligands, receptors, and binding proteins in cancer. J Pathol 2005; 205: 145-153. 
9. Pavelić K, Kolak T, Kapitanović S, et al. Gastric cancer: the role of insulin-like growth factor 2 (IGF 2) and its receptors (IGF 1R and M6-P/IGF 2R). J Pathol 2003; 201: 430-438.

10. Baserga R. The IGF-I receptor in cancer research. Exp Cell Res 1999; 253: 1-6.

11. Ma W, Li W, Fan QX, et al. Expression of IGF-1R in esophageal squamous cell carcinoma and the effect of its silencing by siRNA on the proliferation of esophageal cancer EC9706 cells in vitro. Zhonghua Zhong Liu Za Zhi 2011; 33: 609-612.

12. Pandini G, Vigneri R, Costantino A, et al. Insulin and insulin-like growth factor-I (IGF-I) receptor verexpression in breast cancers leads to insulin/IGF-I hybrid receptor over expression: evidence for a second mechanism of IGF-I signaling. Clin Cancer Res 1999; 5: 1935-1944.

13. Hakam A, Yeatman TJ, Lu L, et al. Expression of insulin-like growth factor-1 receptor in human colorectal cancer. Hum Pathol 1999; 30: 1128-1133.

14. Huang F, Xu LA, Khambata-Ford S. Correlation between gene expression of IGF-1R pathway markers and cetuximab benefit in metastatic colorectal cancer. Clin Cancer Res 2012; 18: $1156-1166$

15. Kim YH, Sumiyoshi S, Hashimoto S, et al. Expressions of insulin-like growth factor receptor- 1 and insulin-like growth factor binding protein 3 in advanced non-small-cell lung cancer. Clin Lung Cancer 2012; 13: 385-390.

16. Pollak M. The insulin receptor/insulin-like growth factor receptor family as a therapeutic target in oncology. Clin Cancer Res 2012; 18: 40-50.

17. Lauren P. The two histological main types of gastric carcinoma: diffuse and so-called intestinal-type carcinoma. Acta Pathol Microbiol Scand 1965; 64: 31-49.

18. Goseki N, Takizawa T, Koike M. Differences in the mode of extension of gastric cancer classified by histological type: new histological classification of gastric carcinoma. Gut 1992; 33: 606-612.

19. Kubo M, Sasako M, Gotoda T, et al. Endoscopic evaluation of the remnant stomach after gastrectomy: proposal for a new classification. Gastric Cancer 2002; 5: 83-89.

20. Vincent AM, Feldman EL. Control of cell survival by IGF signaling pathways. Growth Horm IGF Res 2002; 12: 193-197.

21. Baserga R. The insulin-like growth factor I receptor: a key to tumor growth? Cancer Res 1995; 55: 249-252.

22. Li H, Adachi Y, Yamamoto H, et al. Insulin-like growth factor-I receptor blockade reduces tumor angiogenesis and enhances the effects of bevacizumab for a human gastric cancer cell line MKN45. Cancer 2011; 117: 3135-3147.

23. Ge J, Chen Z, Wu S, et al. Expression levels of insulin-like growth factor- 1 and multidrug resistance-associated protein-1 indicate poor prognosis in patients with gastric cancer. Digestion 2009; 80: 148-158.

24. Jiang Y, Wang L, Gong W, et al. A high expression level of insulin-like growth factor I receptor is associated with increased expression of transcription factor $\mathrm{Sp} 1$ and regional lymph node metastasis of human gastric cancer. Clin Exp Metastasis 2004; 21: 755-764.

25. Matsubara J, Yamada Y, Hirashima Y, et al. Impact of insulin-like growth factor type 1 receptor, epidermal growth factor receptor, and HER 2 expressions on outcomes of patients with gastric cancer. Clin Cancer Res 2008; 14: 3022-3029.

\section{Address for correspondence}

\section{Justyna Zińczuk}

Department of General Pathomorphology

Medical University of Bialystok

Waszyngtona 13

15-269 Bialystok, Poland

e-mail: j.zinczuk@wp.pl 